\title{
Feasibility Analysis on Cryogenic Properties of Supercritical Nitrogen to be used in the Cooling of Hg-Based High Temperature Superconductors for Electric Aircraft Propulsion
}

\author{
Abhinav Kumar, J. V. Muruga Lal Jeyan
}

\begin{abstract}
Electrified Aircraft Propulsion (EAP) and Advanced Hybrid Electric Aircrafts (AHEA) like NASA NX-3, SUGAR, NASA X-57 and STARC ABL are going to be the future of avionics as they have potential to improve fuel economy, emissions and noise levels. The agencies have suggested using superconducting cables for the electric transmission to reduce heat losses. The limit of critical current has reached $134 \mathrm{~K}$ where $\mathrm{Hg}$ - based ceramic materials are available that can superconduct at this temperature range. In order to retain the superconductivity, the cables have to be cooled below its critical temperature. Liquid nitrogen (LN2) boils of at $77 \mathrm{~K}$ which further leads to multiphase heat transfer challenges. An attempt has been made in the present work to overcome such challenges and a novel concept of using Supercritical Nitrogen (SCN), having critical temperature $126.19 \mathrm{~K}$ and pressure as 3.3958MPa (consist single phase), as a cryogen for the cooling of Hg-Based Superconductors, has been introduced. Drastic variations have been found for thermophysical properties of SCN near the critical point. It has been concluded that few temperature and pressure ranges are suitable if one wants to incorporate SCN as cryogen for $\mathrm{Hg}$-based superconductors.
\end{abstract}

Keywords: Electrified Aircraft Propulsion, Supercritical Nitrogen, Hg-Based Superconductors, Superconducting cables, Supercritical Fluids, Hybrid Electric Aircrafts.

\section{INTRODUCTION}

This Electrical Aircrafts are destined to be the future of aviation and propulsion systems as they can provide better outcomes with respect to response time, durability, emissions, safety and economic viability than currently available aviation systems. Recently, a concept of hybrid aircrafts has been widely introduced by the aviation communities as they have to meet the pollution norms imposed by the parent governmental agencies. It includes the contribution of both conventional jet engines technology and novel electric aircraft systems where electrical power can be used in take-off, climbing and landing of the aircraft as it only contributes to $25 \%$ of the total power consumption. In order to reduce the losses during transmission, use of superconducting cables have been suggested by various

Revised Manuscript Received on December 05, 2019

* Correspondence Author

Abhinav Kumar, School of Mechanical Engineering, Lovely Professional University, Phagwara, India. Email: drabhinav@ieee.org

J. V. Muruga Lal Jeyan*, Department of Aerospace Engineering, Lovely Professional University, Phagwara, India. Email: jvmlal@ymail.com researchers [1-5]. As superconducting cables are more efficient than conventional copper cables, thus the former can be used in power transmission from the gas turbine unit to the tail fan used for Boundary Layer Ingesting (BLI) such as in STARC ABL hybrid electric aircraft (Fig. 1).

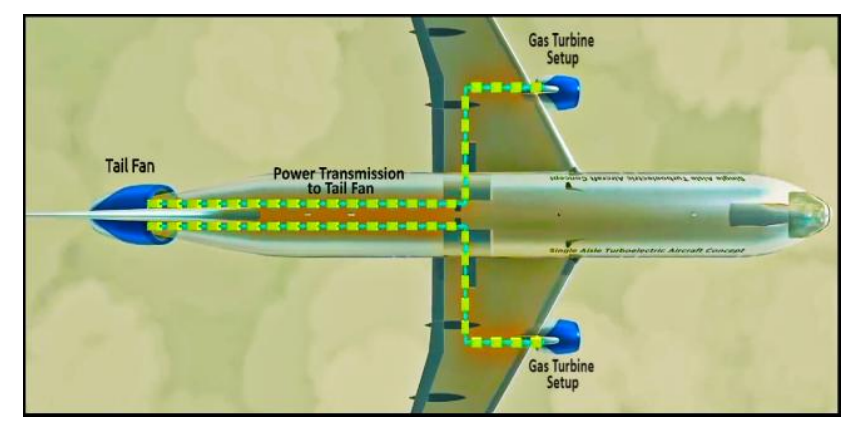

Figure 1. Schematic of STARC ABL hybrid electric aircraft

High temperature superconductors (HTS) are one of eligible contender which have been exploited in various applications such as energy storage [6]-[8], proficient power transmission (transformers or cables) [9]-[11], ship propulsion using motors [12]-[15], power generation (Generators) [16]-[18], and magnetic levitating trains [19][20]. To maintain superconductivity, there is a need to dissipate the heat load generated due to AC losses imposed on the superconducting tape [21]-[23]. These heating loads are required to compensate by an efficient cooling system which may be conduction or convection cooled. In the literature, various studies have been performed where different strategies have been proposed in order to acquire efficient cooling [24][25]. Numerical models have been also intended in order to simulate the LN2 flow behavior [26]-[29]. Few researchers have proposed supercritical cryogens as a novel cryogen due to its astonishing properties in order to achieve efficient cooling [25].

At present, the highest superconducting temperature that can be achieved for HTS is found to be $134 \mathrm{~K}$ and further attempts have been made to expand this bound. However, in order to sustain the superconducting nature of such HTSs, efficient cooling is required. In this context, it is important to invent novel techniques for the efficient cooling of $\mathrm{Hg}$ - Based HTSs by avoiding complexity related with multi-phase physics. 
Therefore, in this study an attempt has been made in introducing a novel cryogen, Supercritical Nitrogen (SCN) having single phase, for the efficient cooling of $\mathrm{Hg}$-Based HTSs. SCN is a fluid coming into existence when it is being pressurized at and above the critical pressure $(3.3958 \mathrm{MPa})$ and heated to a temperature greater than equal to critical temperature (126.19K). It consists liquid like densities and vapor like diffusivities with zero surface tension. At and above critical conditions (Pc and Tc), distinct phase does not exist and interface between liquid and vapor phase disappears.

In the present manuscript, thermophysical properties have been studied which would help in the computational analysis of Hg-Based HTSs used to transmit AC or DC current in electric aircrafts. After analyzing the variations, few temperature ranges have been suggested which would help in achieving the efficient cooling of HTSs. Also, in order to use such properties for the computational studies related to the cooling of $\mathrm{Hg}$-based superconducting tape or cable, a correlation has been developed through simple curve fitting as a function of both temperature and pressure for the SCN. It has been concluded that the correlated properties match excellently with the NIST Database [30].

\section{PROPERTIES OF SUPERCRITICAL NITROGEN}

NIST Database has been used to acquire the thermophysical properties of SCN [31]. In order to observe the property variations, the data has been extracted at and above the critical pressure for large temperature range. To quantify the variation, curve fitting has been done for future use in the computational codes such as MATLAB/ANSYS.

\section{A. SCN Property Variation}

The properties of SCN have been plotted in 2-D for a various ranges of temperature $(127-200 \mathrm{~K})$ and pressure $(3.4$
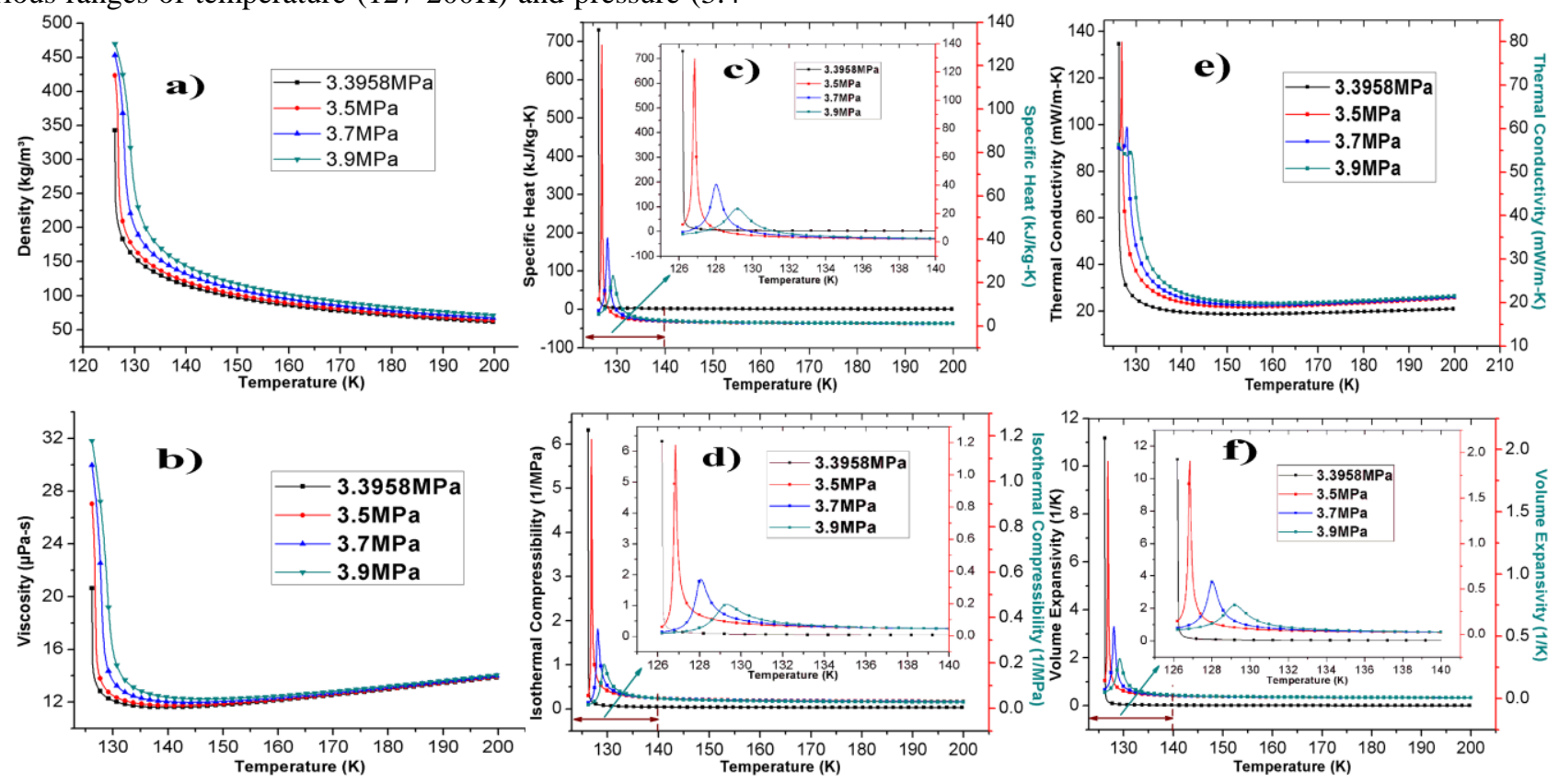

Fig. 2. Variation of Thermophysical Properties with respect to Temperatures at Various Pressures in Supercritical Regime.

to $4 \mathrm{MPa}$ ) in the supercritical regime. In the present manuscript, study has been done above critical temperature practice as fluid can shift its phase to liquid or vapor depending on the extent of pressure drop during the flow.

Fig. 2 (a-f) shows the property variation in the SC regime and it can be seen from the plots that drastic variations have much clear that both density and viscosity experienced a drastic drop with respect to temperature for all pressures and both properties tending to increase with pressure in a help in reducing pumping power required for the cryogen to flow and pressure drop due to friction. From the plots, it can from $127-140 \mathrm{~K}$ as within this range viscosity is variation of specific heat and thermal conductivity in SC regime. From Fig. 1 (c), it is can be noticed that the variation in specific heat is large from Tc to $130 \mathrm{~K}$. It can also be observed that at lower pressures, pseudo-critical point has side of this point. Moderate values of thermal conductivity have been found between a temperature limit varies from 127-140K shown in Fig. 2 (e). As the specific heat value of $\mathrm{SCN}$ is much higher than the liquid and gaseous phase of rates can be achieved.

Fig. 2 ( $d$ and $f$ ) shows the variation of isothermal compressibility and volume expansivity as a function of temperature and pressure which indicate that density is a strong function of pressure and temperature respectively near the critical zone. 
As properties have considerably excellent values within $127-140 \mathrm{~K}$ thus SCN (in a temperature range of $127-133 \mathrm{~K}$ and pressure range varies from 3.4 to $3.7 \mathrm{MPa}$ ) can be employed for the cooling of $\mathrm{Hg}$-Based HTSs which has $\mathrm{Tc}=134 \mathrm{~K}$.

\section{B. Development of Correlations}

Fig. 2 shows the variation in properties with temperature and pressure. Drastic changes in all the properties have been observed near the supercritical region. In order to capture this variation, study has been done from $3.4 \mathrm{MPa}$ to $4 \mathrm{MPa}$ for density, $3.4 \mathrm{MPa}$ to $3.7 \mathrm{MPa}$ for specific heat, viscosity and thermal conductivity.

Table- I: Coefficients for the Properties.

\begin{tabular}{|l|l|l|}
\hline Property & $\begin{array}{l}\text { Density } \\
\text { (25556 Data Points) }\end{array}$ & $\begin{array}{l}\text { Thermal Conductivity } \\
\text { (28804 Data Points) }\end{array}$ \\
\hline $\begin{array}{l}\text { Temperature } \\
\text { Range }\end{array}$ & $\begin{array}{l}\text { 3.4 to 4MPa \& } \\
\text { 127-200K }\end{array}$ & $\begin{array}{l}\text { 3.4 to 3.7MPa } \\
\mathbf{1 2 8 - 2 0 0 K}\end{array}$ \\
\hline $\boldsymbol{p}_{\mathrm{O}}$ & -1488.88727 & -67.1211 \\
\hline $\boldsymbol{a}_{\mathbf{1}}$ & 15.84905 & 0.84238 \\
\hline $\boldsymbol{a}_{\mathbf{2}}$ & 0.02428 & 0.04027 \\
\hline $\boldsymbol{a}_{3}$ & $9.17951 \mathrm{E}-05$ & $2.00016 \mathrm{E}-04$ \\
\hline $\boldsymbol{a}_{\mathbf{4}}$ & $2.42961 \mathrm{E}-06$ & $-7.94729 \mathrm{E}-07$ \\
\hline $\boldsymbol{b}_{\mathbf{1}}$ & -196.192 & -12.9664 \\
\hline $\boldsymbol{b}_{2}$ & -27.5371 & 1.62166 \\
\hline $\boldsymbol{b}_{3}$ & 14.14434 & -0.21479 \\
\hline $\boldsymbol{b}_{4}$ & -5.4047 & -3.69915 \\
\hline $\boldsymbol{b}_{5}$ & 0.71559 & 0.43753 \\
\hline $\mathrm{R}^{2}$ Value & $\mathbf{0 . 9 8 6}$ & $\mathbf{0 . 9 9 4}$ \\
\hline
\end{tabular}

Due to abrupt changes in properties curve fitting becomes bit complex using single correlation, consequently non-linear piecewise modeling has been performed to match the properties with NIST data with premier correctness and least error. In order to capture the variation in density, viscosity and thermal conductivity of SCN, a two statistical models have been employed successfully (1) and (2). The proposed statistical models show a great reliability while retracing the NIST property data.

$$
\begin{aligned}
& (\rho, \mu, k)=\frac{p_{0}+a_{1} T+b_{1} P+b_{2} P^{2}+b_{3} P^{3}}{1+a_{2} T+a_{3} T^{2}+a_{4} T^{3}+b_{4} P+b_{5} P^{2}} \\
& \left(c_{p}\right)=a_{2}+\frac{\left(a_{1}-a_{2}\right)}{1+\exp \left(\left(T_{0}-T\right) / p\right)}
\end{aligned}
$$

$$
\begin{gathered}
\mathbf{R}^{2}=1-\frac{\sum_{\mathrm{i}=1}^{N}\left(\mathrm{f}_{\mathrm{i}}^{\mathrm{cal}}-\mathrm{f}_{\mathrm{i}}^{\text {nist }}\right)^{2}}{\sum_{\mathrm{i}=1}^{N}\left(\mathrm{f}_{\mathrm{i}}^{\mathrm{cal}}-\mathrm{f}_{\mathrm{i}}^{\text {mean }}\right)^{2}} \\
\text { where } \mathrm{f}_{\mathrm{i}}^{\text {mean }}=\frac{1}{\mathrm{~N}} \sum_{\mathrm{i}=1}^{\mathrm{n}} \mathrm{f}^{\mathrm{cal}}
\end{gathered}
$$

Here ' $\mathrm{f}$ ' represents the thermophysical property and Fig. 3 (R-1 and R-2) indicates the Percent Relative Error (PRE) which is found to higher at critical region and is increasing with pressures.

Where $\mathrm{T}$ is temperature in ' $\mathrm{K}$ ', $\mathrm{P}$ is pressure in ' $\mathrm{MPa}$ ' and all others are constants. As in the vicinity of the critical region, abrupt variations in almost all the properties have been found as shown in Fig. 2, thus, few temperature points have been excluded $(1 \mathrm{~K}$ for thermal conductivity and $2 \mathrm{~K}$ for viscosity) while estimating the properties. Individual numbers of data points that have been used to generate correlation are mentioned in the Table I to Table III. The correlation coefficients for the density, thermal conductivity, viscosity and specific heat have been tabulated in Table I to Table III.

Table- II: Correlation Coefficients for Viscosity

\begin{tabular}{|l|l|l|l|l|}
\hline \multirow{2}{*}{ Property } & \multicolumn{4}{|c|}{ Viscosity $(\mu$ Pa-s) $(\mathbf{2 8 8 0 4}$ Data Points) } \\
\cline { 2 - 5 } & $\mathbf{3 . 4}$ to 3.5MPa & $\mathbf{1 4 2 . 0 1 - 2 0 0 K}$ & $\mathbf{1 2 8}-142 \mathrm{~K}$ & $\mathbf{1 4 2 . 0 1 - 2 0 0 K}$ \\
\hline Temperature Range & $\mathbf{1 2 8 - 1 4 2 K}$ & 3.80427 & 109.65576 & 9.0723 \\
\hline $\boldsymbol{p}_{\mathrm{O}}$ & 762.791 & -0.06006 & 9.45769 & -0.05278 \\
\hline $\boldsymbol{a}_{1}$ & 11.42879 & 0.0053 & 1.41032 & 0.00494 \\
\hline $\boldsymbol{a}_{\mathbf{2}}$ & 2.33314 & $-7.875 \mathrm{E}-05$ & $-3.75652 \mathrm{E}-04$ & $-6.64554 \mathrm{E}-05$ \\
\hline $\boldsymbol{a}_{3}$ & 0.01466 & $1.76232 \mathrm{E}-07$ & $-8.34311 \mathrm{E}-06$ & $1.46159 \mathrm{E}-07$ \\
\hline $\boldsymbol{a}_{4}$ & $-9.41082 \mathrm{E}-05$ & 5.87119 & -46.23624 & -1.98784 \\
\hline $\boldsymbol{b}_{1}$ & 17.83937 & -1.16291 & -29.84038 & 1.40265 \\
\hline $\boldsymbol{b}_{2}$ & -51.10889 & 0.13137 & -14.11282 & -0.16724 \\
\hline $\boldsymbol{b}_{3}$ & -32.53264 & -0.21414 & -17.54259 & -0.3114 \\
\hline $\boldsymbol{b}_{4}$ & -51.19926 & 0.05704 & -6.68614 & 0.05767 \\
\hline $\boldsymbol{b}_{5}$ & -11.67908 & $\mathbf{0 . 9 9 8}$ & $\mathbf{0 . 9 3}$ & $\mathbf{0 . 9 9}$ \\
\hline $\mathrm{R}^{2}$ Value & $\mathbf{0 . 9 8 2}$ & & \\
\hline
\end{tabular}


Feasibility Analysis on Cryogenic Properties of Supercritical Nitrogen to be used in the Cooling of Hg-Based High Temperature Superconductors for Electric Aircraft Propulsion

Table- III: Correlation Coefficients for Specific Heat

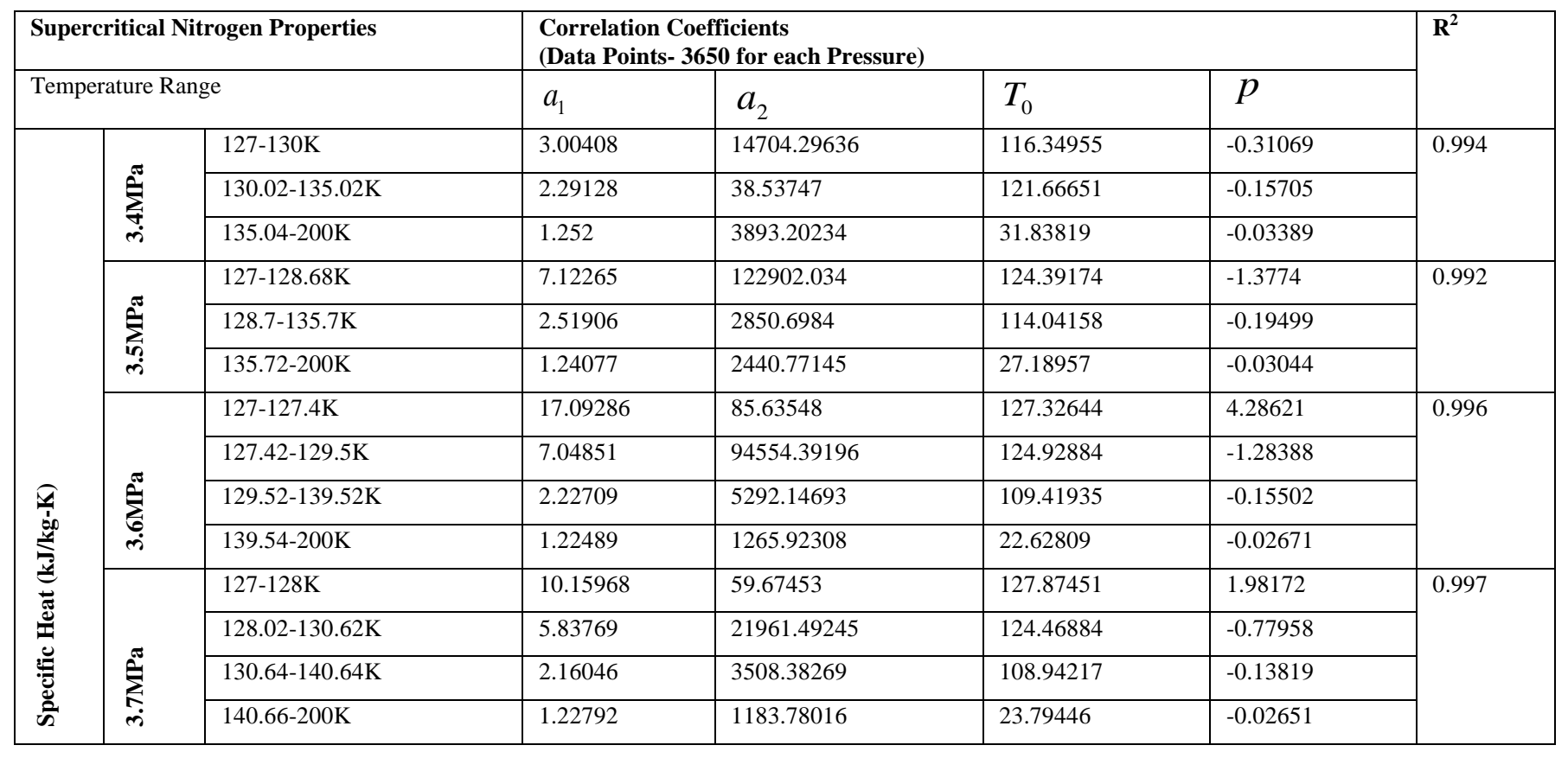
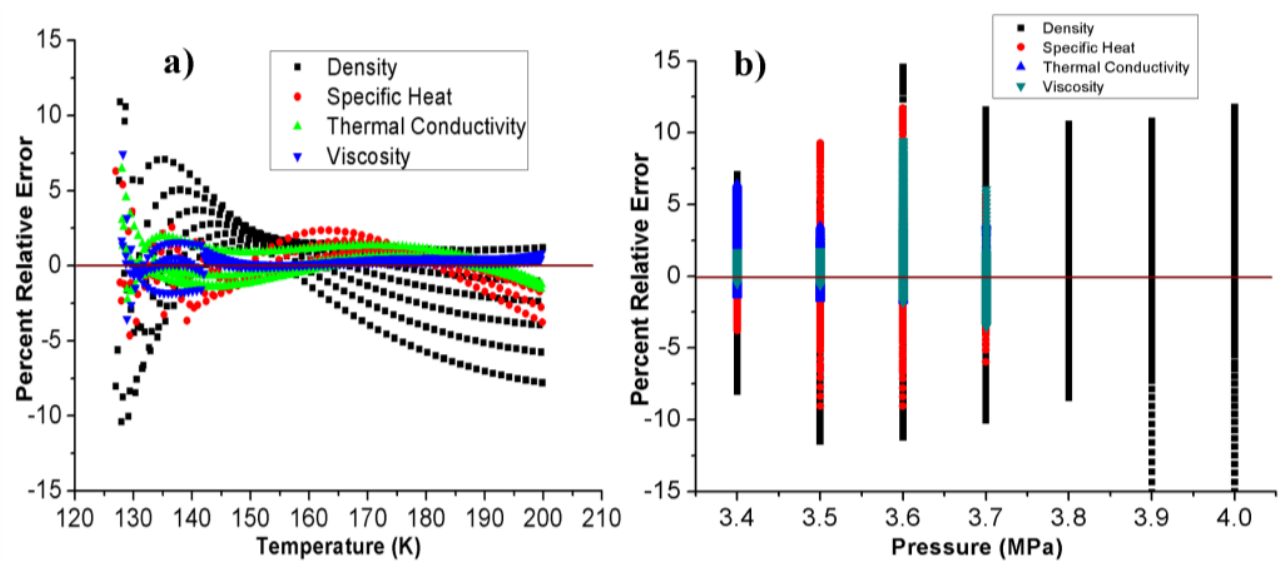

Fig. 3. Error Analysis for the Developed Correlations

Table- IV: AARE and SAR Values

\begin{tabular}{|l|l|l|l|l|}
\hline SCN & \multicolumn{2}{|l|}{ Pressure Range } & AARE (\%) & SAR \\
\hline Density & 3.4 to $4 \mathrm{MPa}$ & 2.51 & 79844 \\
\hline $\begin{array}{l}\text { Thermal } \\
\text { Conductivity }\end{array}$ & \multicolumn{2}{|l|}{3.4 to $3.7 \mathrm{MPa}$} & 0.74 & 4568 \\
\hline \multirow{5}{*}{ Viscosity } & 3.4 to & $128-142 \mathrm{~K}$ & 0.29 & 12.15 \\
& $3.5 \mathrm{MPa}$ & $142.01-200 \mathrm{~K}$ & 0.19 & 285 \\
\cline { 2 - 5 } & 3.6 to & $128-142 \mathrm{~K}$ & 1.62 & 582 \\
& $3.7 \mathrm{MPa}$ & $142.01-200 \mathrm{~K}$ & 0.35 & 534 \\
\hline \multirow{5}{*}{ Specific } & $3.4 \mathrm{MPa}$ & & 1.6 & 103 \\
Heat & $3.5 \mathrm{MPa}$ & $127-200 \mathrm{~K}$ & 1.32 & 132 \\
& $3.6 \mathrm{MPa}$ & & 1.02 & 158 \\
& $3.7 \mathrm{MPa}$ & & 0.88 & 117 \\
\hline
\end{tabular}

Therefore, these equations can be incorporated in the simulation packages via using user defined functions in order to capture the physics changing w.r.t. temperature and pressure. Different statistical factors like AARE (\%) and SAR have been estimated and lower values (Table IV) show correctness of the fit [25]. $\mathrm{R}^{2}$ Value is found to approximate equal to 1 .

\section{CONCLUSION}

From the present study it has been concluded that SCN can be employed as a cryogen in order to sustain the superconductivity of $\mathrm{Hg}$-Based High Temperature Superconductors for a temperature limit of 127-133K. As properties are considerably excellent within $127-140 \mathrm{~K}$ thus SCN (in a temperature range of $127-133 \mathrm{~K}$ and pressure range of 3.4 to $3.7 \mathrm{MPa}$ ) can be employed for the cooling of $\mathrm{Hg}$-Based HTSs used in electric aircraft applications which has Tc=134K. Moreover, developed correlations show good accuracy in estimating viscosity, thermal conductivity and specific heat. Near the critical point as density is a strong function of temperature and pressure thus large errors are associated in estimating its value near Tc and $\mathrm{Pc}$ as shown in Fig. 4 ( $a$ and b). Developed correlation can be implemented in the simulation software using user defined functions in order to capture precise physics related to flow and heat transfer characteristics. 


\section{REFERENCES}

1. S. Samoilenkov et al., "Effective Management of MVA-range electric Power in Aircraft enabled by high Tc superconducting systems," presented at More Electric Aircraft, Toulouse, France, Feb. 2015.

2. "Strategic Research and Innovation Agenda (SRIA)." Advisory Council for Aeronautics Research in Europe (ACARE) (2012) [Online]. Available: http://www.acare4europe.org/sria, Accessed on 12 May 2019.

3. "HTS Triax ${ }^{\mathrm{TM}}$ energy cable systems," NKT Cables (2008) [Online]. Available:

http://www.nktcables.com/ /media/Files/NktCables/download\%20files /com/HTS-Triax_engl_061108.pdf, Accessed on 12 May 2019.

4. Kario, "Superconducting properties of Roebel coated conductor cable from Superpower and SuperOx tapes with different transposition length," presented at CCA-2014, Jeju, Korea, Nov. 2014.

5. S. S. Fetisov et al., "Development and Characterization of a 2 G HTS Roebel Cable for Aircraft Power Systems," in IEEE Transactions on Applied Superconductivity, vol. 26, no. 3, pp. 1-4, April 2016, Art no. 4803204. doi: 10.1109/TASC.2016.2549036

6. A. Kumar and R. Kaur, "Electromagnetic analysis of $1 \mathrm{MJ}$ class of high temperature superconducting magnetic energy storage (SMES) coil to be used in power applications," vol. 050003, p. 050003, 2018.

7. A. Morandi et al., "Design and Comparison of a 1-MW / 5-s HTS SMES With Toroidal and Solenoidal Geometry," vol. 26, no. 4, pp. 1-6, 2016.

8. Abhinav Kumar, J V Muruga Lal Jeyan, Ashish Agarwal, Numerical analysis on $10 \mathrm{MJ}$ solenoidal high temperature superconducting magnetic energy storage system to evaluate magnetic flux and Lorentz force distribution, Physica C: Superconductivity and its Applications, Volume 558, 2019, Pages 17-24. https://doi.org/10.1016/j.physc.2019.01.001.

9. M. Ohya et al., "In-grid Demonstration of High-temperature Superconducting Cable,” Phys. Procedia, vol. 45, pp. 273-276, 2013.

10. C. H. Kim, S.-K. Kim, L. Graber, and S. V Pamidi, "Cryogenic Thermal Studies on Terminations for Helium Gas Cooled Superconducting Cables," Phys. Procedia, vol. 67, pp. 201-207, 2015.

11. N. G. Suttell, J. V. C. Vargas, J. C. Ordonez, S. V Pamidi, and C. H. Kim, "Modeling and optimization of gaseous helium (GHe) cooled high temperature superconducting (HTS) DC cables for high power density transmission," Appl. Therm. Eng., vol. 143, pp. 922-934, 2018.

12. H. Ohsaki and Y. Tsuboi, "Study on electric motors with bulk superconductors in the rotor," J. Mater. Process. Technol., vol. 108, no. 2, pp. 148-151, 2001.

13. P. Tixador, "Superconducting electrical motors," Int. J. Refrig., vol. 22, no. 2, pp. 150-157, 1999.

14. D. Driscoll, V. Dombrovski, and B. Zhang, "Development status of superconducting motors," IEEE Power Eng. Rev., vol. 20, no. 5, pp. $12-15,2000$.

15. C. D. Manolopoulos, M. F. Iacchetti, A. C. Smith, K. Berger, M. Husband, and P. Miller, "Stator Design and Performance of Superconducting Motors for Aerospace Electric Propulsion Systems," IEEE Trans. Appl. Supercond., vol. 28, no. 4, pp. 1-5, 2018.

16. M. Furuse, S. Fuchino, M. Okano, N. Natori, and H. Yamasaki, "Development of a cooling system for superconducting wind turbine generator," Cryogenics (Guildf)., vol. 80, pp. 199-203, 2016

17. A. B. Abrahamsen et al., "Feasibility study of 5MW superconducting wind turbine generator," Phys. C Supercond. its Appl., vol. 471, no. 21, pp. 1464-1469, 2011.

18. V. M. R. Zermeno, A. B. Abrahamsen, N. Mijatovic, M. P. Sorensen, B. B. Jensen, and N. F. Pedersen, "Simulation of an HTS Synchronous Superconducting Generator,” Phys. Procedia, vol. 36, pp. 786-790, 2012.

19. J. Xie, P. Zhao, Z. Jing, C. Zhang, N. Xia, and J. Fu, "Research on the sensitivity of magnetic levitation (MagLev) devices," J. Magn. Magn. Mater., vol. 468, pp. 100-104, 2018.

20. L. Schultz and M. M. B. T.-R. M. in M. S. and M. E. Arafat,

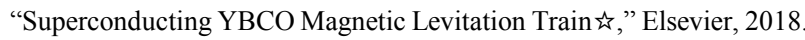

21. J. A. Demko et al., "Practical AC loss and thermal considerations for HTS power transmission cable systems," IEEE Trans. Appl. Supercond., vol. 11, no. 1, pp. 1789-1792, 2001.

22. H. Noji, K. Haji, and T. Hamada, "AC loss analysis of 114 MVA high-Tc superconducting model cable," Phys. C Supercond., vol. 392-396, pp. 1134-1139, 2003.

23. H. Noji, K. Ikeda, K. Uto, and T. Hamada, "Numerical analysis of the AC loss in a high-TC superconducting cable measured by calorimetric method," Phys. C Supercond., vol. 425, no. 3, pp. 97-100, 2005.
24. J. A. Demko and R. C. Duckworth, "Cooling Configuration Design Considerations for Long-Length HTS Cables," IEEE Trans. Appl. Supercond., vol. 19, no. 3, pp. 1752-1755, 2009.

25. A. Kumar, P. R. Usurumarti, and R. S. Dondapati, "Comparison between the thermophysical properties of compressed LOX and supercritical oxygen to be used as cryogen in HTS power applications," in IET Conference Publications, 2016, vol. 2016, no. CP739.

26. H.-M. Chang, K. N. Ryu, and H. S. Yang, "Cryogenic design of liquid-nitrogen circulation system for long-length HTS cables with altitude variation," Cryogenics (Guildf)., vol. 83, pp. 50-56, 2017.

27. L. Jin, C. Lee, S. Baek, and S. Jeong, "Design of high-efficiency Joule-Thomson cycles for high-temperature superconductor power cable cooling," Cryogenics (Guildf)., vol. 93, pp. 17-25, 2018.

28. H.-M. Chang, K. N. Ryu, and H. S. Yang, "Integrated design of cryogenic refrigerator and liquid-nitrogen circulation loop for HTS cable," Cryogenics (Guildf)., vol. 80, pp. 183-192, 2016.

29. M. Furuse, S. Fuchino, and N. Higuchi, "Counter flow cooling characteristics with liquid nitrogen for superconducting power cables," Cryogenics (Guildf)., vol. 42, no. 6, pp. 405-409, 2002.

30. E. W. Lemmon, M. O. Mclinden, and M. L. Huber, "NIST standard reference database, physical and chemical properties division,' version7. 0, beta, vol. 7, no. 30, p. 2.

31. E. W. Lemmon, M. L. Huber, and M. O. McLinden, "NIST reference fluid thermodynamic and transport properties-REFPROP," NIST Stand. Ref. database, vol. 23, p. v7, 2002.

\section{AUTHORS PROFILE}

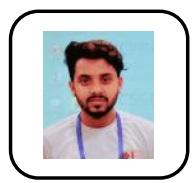

Abhinav Kumar is pursuing his Doctorate in Mechanical Engineering from Lovely Professional University, Punjab, India. He has completed his master's in thermal engineering specialization from Lovely Professional University in 2014 and bachelor's in Mechanical Engineering from Punjab Technical University in 2011. He has published many SCI and Scopus indexed articles in various journals and has attended many international conferences. His area of research is vast including superconducting magnetic energy storage systems, superconducting fault current limiters, high temperature superconducting cable design \& cooling, cryogenic fluid properties, nozzle cooling, computational fluid dynamics and solar energy storage systems. He is one of the reviewers for SCI and Scopus indexed journals and conferences. $\mathrm{He}$ has been awarded with University Academic Honor and University Honor Roll for his excellent academic records. He is holding Student IEEE and life membership of Indian Society of Heat and Mass Transfer (ISHMT).

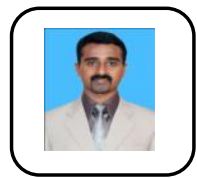

Dr. JV Muruga Lal Jeyan works with High speed aerodynamics, wind tunnel instrumentation and testing, Was board member of EI Singapore 3 years, 12 plus years of experience in the field of academic, industry and research owner of John plaza shopping mall \& Vijaya apartments. Around 9 years served as Head of Aviation Studies in various University. Had an excellent number of students working under in various topics in and around India. Received RASHTRIYA GAURAV AWARD for meritorious service, by former governor of Tamilnadu \& Assam at a seminar on economic Growth \& National Integration at New Delhi. life member of 1) Aeronautical society of India 2) IAETSD 3) The institute of engineers IE 4) The Indian Science congress ISC Editorial Board Member for few international journals. 